\title{
Were the First Europeans Pale or Dark Skinned?
}

\author{
Clyde Winters \\ Uthman dan Fodio Institute, Chicago, USA \\ Email: olmec982000@yahoo.com
}

Received 5 March 2014; revised 2 April 2014; accepted 28 April 2014

Copyright (C) 2014 by author and Scientific Research Publishing Inc.

This work is licensed under the Creative Commons Attribution International License (CC BY). http://creativecommons.org/licenses/by/4.0/

c) (i) Open Access

\begin{abstract}
This is an overview of the Out of Africa (OoA) settlement of Europe during the Aurignacian period. Klyosov claims that the first Europeans were fair (pale) skin, and Neanderthal who never lived in Africa. Archaeological evidence indicated that Neanderthals originated in Africa and between 139 kya and 125 kya the Neanderthals migrated back into Africa and spread from Morocco to East Africa. The archaeological, anthropological and genetic evidence indicated that the first Europeans were dark skin Sub-Saharan Africans who carried mtDNA haplogroup N and Y-chromosome C6 into Europe.
\end{abstract}

\section{Keywords}

Haplogroup, Neanderthal, Phenotype, Skeletal, Mousterian, mtDNA, SLC24A5

\section{Introduction}

Were the first Europeans dark or pale skinned? Klyosov (2014), argued that the Neanderthals and ancient Europeans were fair (pale) skin and that most African haplogroups were the result of a back migration of pale skinned Europeans. Klyosov (2014) claimed that archaeology and paleoanthropology data of African skeletal material did not tell us much about the origin of African and non-African populations. Finally, Klyosov (2014) argued that that there was no archaeological proof of the appearance of anatomically modern humans (AMH) in Africa dating before 100 kya. He wrote:

"Ancestors of the most present-day non-Africans did not come from Africa in the last 30,000 - 600,000 years at least. In other words, those who migrated from Africa, or were forcefully taken out as slaves, are not ancestors of the contemporary Europeans, Asians, Native Americans, Australians, Polynesians. This follows from the whole multitude of data in anthropology, genetics, archaeology, DNA genealogy. Study of the DNA of excavated bones of Neanderthals has shown in them MCR1 melanocortin receptor, in the same 
variant as that in modern humans, which makes pale skin and red hair, observed in modern humans (Lalueza-Fox et al., 2007), though, according to the study authors, humans did not inherit MCR1 from Neanderthals. There was not any data that Neanderthals were Black Africans. Indeed, no Neanderthals were found in Africa."

Although this is the opinion of Klyosov (2014) the archaeological and genetic evidence does not support his conclusion. The skeletal and archaeological evidence made it clear that the first Europeans were probably dark skin, not pale skin.

\section{Materials and Methods}

This research was conducted at the Uthman dan Fodio Institute in Chicago. The samples for this study includes published research literature on population movements from Africa into Western Eurasia. Craniometric, genomic and archaeological literature relating to African and Eurasian population movements was critically analyzed focusing on haplogroup L3(N) and $\mathrm{H}$.

\section{Results}

\subsection{Neanderthals}

Klyosov (2014) claims that there were no Neanderthal populations in Africa. This is false. This is not based on what we know about African archaeology.

The archaeological research makes it clear Neanderthal probably mixed with Africans. As early as 200 kya homo sapien sapie ns originated in Africa.

Probably 400 - 600 kya Homo rhodesiensis migrated into Europe. Homo rhodesiensis originated in Africa. The ancestor of neanderthal man was Homo rhodesiensis. Between 139 kya and 125 kya the Neanderthals migrated back into Africa and spread from Morocco to East Africa (Ki-Zerbo, 1981: p. 572).

The Neanderthal used Mousterian tools. These tools were also being used in Africa as early 130 kya. This places Neanderthalers in North Africa.

The human types associated with the Neanderthal tools found at Jebel Ighoud and Haua Fteah resemble contemporaneous European Neanderthaler tools. The presence of Mousterian tools suggest that Neanderthalers mixed with Africans because we know that anatomically modern humans were living in the area at the time.

The African Neanderthal people used the common Levoiso-Mousterian tool kit originally discovered in Europe. The Nenderthal skeletons mainly come from Djebel Irhoud and El Guettar (Ki-Zerbo, 1981). Later Neanderthal people used the Aterian tool kit.

\subsection{Pigmentation Gene}

The popular view of the ancient Europeans is that they were pale-faced homo sapien sapiens. This is the view of Klyosov (2014).

Even though Klyokov (2014) maintains that the first anatomically modern human (AMH) were pale faced the research indicates a probable Paliolithic origin for the "light" pigment gene.

The functional alleles in the human pigmentation pathway include 3 genes: HERCZ, SLC24A5, and TYR. HERCZ provides the eye color to individuals. The HERCZ gene is found among dark skinned population like the Luyha and Maasai who live in East Africa.

Researchers have suggested that natural selection played a role in skin pigmentation. A popular hypothesis for light pigmentation in Europe is that the further away from the equator a population lives, due to decreasing exposure to sun light, in the high latitudes, decreased solar ultraviolet light results in decreased pigmentation. Decreased pigmentation alledgedly results from greater synthesis of dermal vitamin D.

The pigmentation center is SLC24A5. The ancestral gene for light skin rs1426L54 is "predominante" among sub-Saharan African (SSA) populations (Canfield et al., 2014). The derived allele from this coding polymerphism for light skin is A111T alleles (Canfield et al., 2014). The A111T pigmentation haplotype indicate high frequencies among "light skinned” populations in Europe and East Asia.

The highest frequencies of SLC24A5 ${ }^{\mathrm{A} 111 \mathrm{~T}}$ are found in Western Europeans. Interestingly, the lowest global frequencies of SLC24A5 ${ }^{\text {A111T }}$ are found in SSA, the Polar Region and East Asia (EA) (Canfield et al., 2014). The frequency of A111T haplotype in EA and SSA is 0.15, while in Western Eurasia the average frequency of 
this mutation is 0.9 - 1.0 (Canfirld et al., 2014). The low frequency of A111T among non-western Eurasians suggest that this mutation may only account for pale skin pigmentation in Western Eurasia.

\subsection{Origin of Dark Skinned AMH via IBERIA or the Levant}

The evidence makes it clear that the first Europeans were dark skinned. Olalde et al. (2014) provides conclusive genetic evidence that hunter gatherers in Mesolithic Europe were dark skinned or highly pigmented with light (blue) eyes. The Olalde et al. (2014) study of La Brana-Arintero site in Leon, Spain of dark skinned hunter-gatherer Europeans corresponds to the Loschbour sample from Luxembourg, of dark skinned Europeans. This cline of pigmentation in western Eurasia appears to be associated with Cro-Magnon man, the first AMH in western Europe who was associated with the Aurignacian culture.

The first AMH European reconstructed by Forensic artist Richard Neave, of National Geographic from 35 kya resembled a Khoisan individual. This supports the research of Boule and Vallois (1957) that South Africans migrated across Africa, into Europe over 35 kya.

Most researchers maintain that the first AMH European came from the Levant. This migration of AMH entering western Eurasia from the East is not supported by the archaeological evidence. The Auriganacian culture which is associated with the Cro-Magnon people crossed the Straits of Gibraltar (SG) from Africa into Iberia (Winters, 2008, 2011).

We know that the first AMH probably entered western Eurasia via the SG, because Neanderthals dominated the Levant until around 30 - 20 kya. Between 10 - 5 kya the Levant population was "tropically adapted" hominids, especially in relation to Qafzed-Skhul (QS) hominids (Holliday, 2000). Ninety-five percent of the QS population were SSA (e.g., Qafzeh 8 at 85\%, and Skhul 4 at 71\%) (Holliday, 2000).

The fauna and zooarchaeological remains from QS, indicate the hominids here exploited African fauna (Holliday, 2000). Holliday (2000) claims the QS people were Proto-Cro-Magnons, because they were similar in dental and craniological size to the Aurignacian hominids (Holliday, 2000). Except of the AMH at QS, the majority of hominids in the Levant were Neanderthal.

The craniometric evidence for SSA populations in Europe was also examined by Brace et al. (2006). Brace et al. (2006) after studying 24 craniofacial measurements of AMH from Europe was surprised to find that Neolithic people in Europe fail to be related to modern Europeans. Some researchers have assumed that the Basque, a non-Indo-European population in Spain probably represented descendants of the original Europeans, but samples from this group and Canary Islanders did not correspond to the Natufians or Cro-Magnon populations (Brace, 2006).

The founders of civilization in Southwest Asia were the people, archaeologists call Natufians. By 13,000 BC, according to Clark (1977) the Natufians were collecting grasses in Nubia (Ehret, 1979), which later became domesticated crops in Southwest Asia. In Palestine the Natufians established intensive grass collection. The Natufians used the Ibero-Maurusian tool industry (Wendorf, 1968).

The Aurignacian civilization was founded by the Cro-Magnon people who originated in Iberia. They took this culture to Western Europe across the Straits of Gibraltar (Winters, 2011). The Cro-Magnon people were probably Bushman/Khoisan (Boule \& Vallois, 1957).

The "Classic Aurignacian" culture probably began in Africa, crossed the Straits of Gibraltar into Iberia, and expanded eastward across Europe (Brown, 2006; Gilead, 2005; Steven et al., 2001; Winters, 2008, 2011). The archaeological record informs us that Cro-Magnon people replaced the Neanderthal population of the Levant, at Ksar Akil around 32,000 years ago (Steven et al., 2001; Gilead, 2005), not the Natufians who entered the Levant almost 20,000 years later. This indicates that the Aurignacians moved west to east from Iberia across Europe.

The archaeological and craniometric evidence indicates that the pre-Indo-European people were probably highly pigmented. There have been numerous "Negroid skeletons" found in Europe according to Boule and Vallois (1957). Diop (1991) discussed the Negroes of Europe in Civilization or Barbarism (pp. 25-68). Also W.E. B. DuBois, The World and Africa noted that "There was once a an "uninterrupted belt' of Negro culture from Central Europe to South Africa” (p. 88).

Boule and Vallois (1957) reported the find of SSA skeletons at, Grotte des Enfants, Chamblandes in Switzerland, several Ligurian and Lombard tombs of the Metal Ages have also yielded evidences of a Negroid element.

Since the publication of Verneau's memoir, discoveries of other Negroid skeletons in Neolithic levels in Illyria and the Balkans have been announced. The prehistoric statues, dating from the Copper Age, from Sultan Selo 
in Bulgaria are also thought to protray Negroids (Boule \& Vallois, 1957).

In 1928 Rene Bailly found in one of the caverns of Moniat, near Dinant in Belgium, a human skeleton of whose age it is difficult to be certain, but seems definitely prehistoric. It is remarkable for its Negroid characters, which give it a reseblance to the skeletons from both Grimaldi and Asselar (Diop, 1991).

Boule and Vallois (1957), was able to chart the migration of civilization from South Africa to the Aurignacian culture of Europe. These anthropologist reported that the Khoisan shared the same style stone implements and burials "associated with the Aurignacian or Solutrean type industry..." (Boule \& Vallois, 1957: pp. 318-319). They add, that in relation to Bushman [Khoisan] art "This almost uninterrupted series leads us to regard the African continent as a centre of important migrations which at certain times may have played a great part in the stocking of Southern Europe. Finally, we must not forget that the Grimaldi Negroid skeletons show many points of resemblance with the Bushman [Khoisan] skeletons” (Boule \& Vallois, 1957).

\subsection{Haplogroups in Ancient Europe}

Most of the haplogroups associated with Eurasian populations are derived from L3(M, N). Winters (2010) has argued that L3(M, N) spread across Africa before the Out of Africa (OoA) event 60 kya.

Researchers have found that western Eurasians carry some Neanderthal genes. There is little evidence of Neanderthal genes among African populations. An exception to this norm are the Khoisan who share a phylogenic relationship with Altai Neanderthals (Prufer et al., 2014).

The traditional view for the spread of L3(M, N) across Eurasia is that the $\mathrm{M}$ and $\mathrm{N}$ macrohaplogroups originated in western Eurasia and returned to Africa as a result of back-migration. The big problem for this theory is that the proposed dates for the origin of haplogroups $\mathrm{N}$ and $\mathrm{M}$ in western Europe, date to a period when these areas were inhabited by Neanderthal people-not AMH. This supports an African origin for L3(M, N).

The craniometric evidence supports a Khoisan presence in Europe during Aurignacian times. If the Khoisan represent the ancient dark skinned European population, this reality should be able to be confirmed by genetic research.

The most archaic AMH remains come from Florished, South Africa; they date between 190 - 330 kya (Rito et al., 2013). Other ancient fossil evidence of AMH in South Africa come from Broken Hill (c. 110 kya) and the Klasis River caves (c. 65 - 105 kya).

Researchers have been surprised to find Khoisan and European admixture. The idea that the Khoisan acquired Eurasian admixture via Ethiosemitic speakers is pure speculation (Pickrell et al., 2013). There is no archaeological evidence of Ethiopians migrating into East and South Africa, but there is evidence of an ancient migration of Khoisan into Europe based on archaeological and skeletal data.

The Khoisan carry haplogroups L3(M, N). Before they reached Iberia, they probably stopped in West Africa.

The basal L3(M) motiff in West Africa is characterized by the Ddel site np 10,394 and Alul site np 10,397 associated with AF-24. This supports my contention that Khoisan speakers early settled West Africa on their way to Iberia.

Granted L3 and L2 are not as old as LOd, but Gonder et al. (2006) provides very early dates for this mtDNA e.g., L3(M, N) 94.3; the South African Khoisan (SAK) carry L1c, L1, L2, L3 M, N dates to 142.3 kya; the Hadza are L2a, L2, L3, M, N, dates to 96.7 kya.

The dates for L1, L2, L3, M, N are old enough for the Khoisan to have taken N to West Africa, where we find L3, L2 and LOd and thence to Iberia as I suggested in my paper (Winters, 2011).

It is interesting to note that LO haplogroups are primarily found among Khoisan and West Africans. This shows that at some point in prehistory the Khoisan had migrated into West Africa.

The first modern European reconstructed by Forensic artist Richard Neave based on skull fragments from 35,000 years ago resembled a Khoisan (Figure 1). The skull was discovered in the southwest region of Romania's Carpathian Mountains. This supports the research of Boule and Vallois that South Africans migrated into Europe 35 kya. This genetic evidence now supports Boule and Vallois of a Khoisan migration into Europe.

The Khoisan may have introduced the L haplogroup to Iberia. The SAK populations carry haplogroups L2, and L3. de Domínguez (2005), noted that much of the ancient mtDNA found in Iberia has no relationship to the people presently living in Iberia today and correspond to African mtDNA haplogroups.

de Domínguez (2005) found that the lineages recovered from ancient Iberian skeletons are the African lineages L1b, L2 and L3. Almost 50\% of the lineages from the Abauntz Chalcolithic deposits and Tres Montes, in 


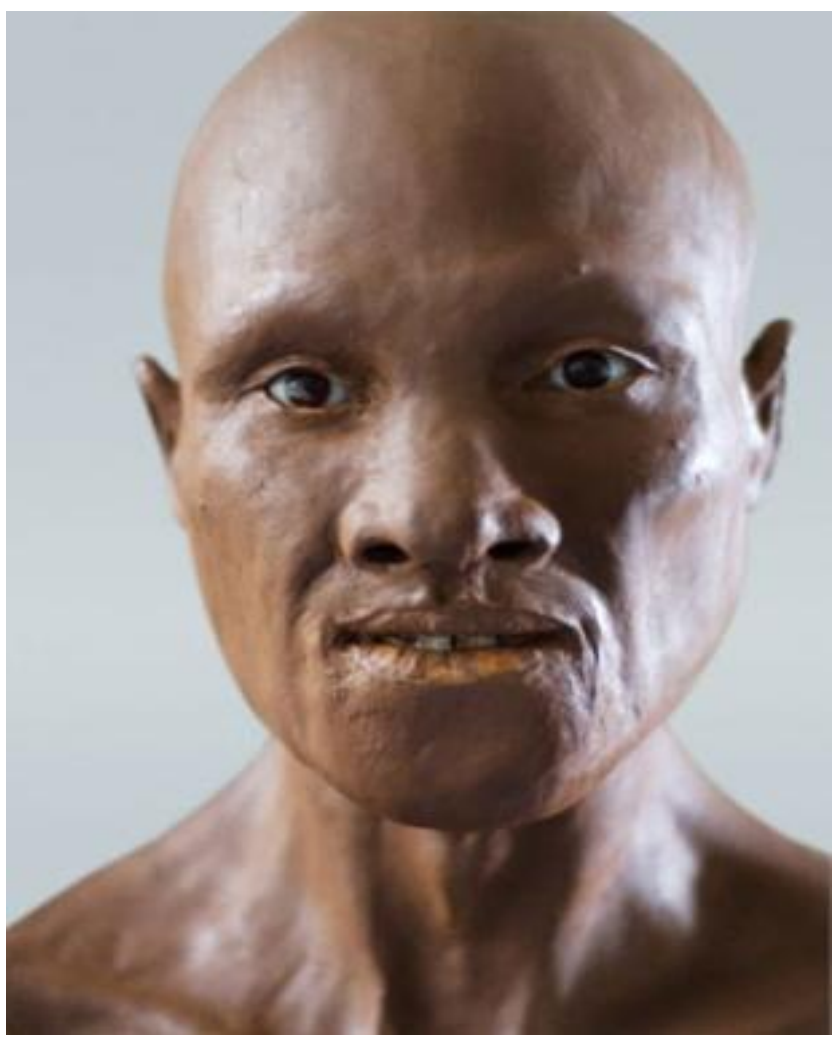

Figure 1. First European.

Navarre are the Sub-Saharan lineages L1b, L2 and L3. The appearance of phylogenetically related sequences of hg L3 present in many ancient Iberian skeletons suggest that this haplogroup may have a long history in Iberia. This would support the possibility that South African Khoisan (SAK) populations early settled ancient Iberia.

Haak et al. (2005) argue that a genetic analysis of ancient mtDNA suggest that the neolithic population of Europe originated in Eurasia. The archaeology, craniometric, phylogeographic and genetic evidence trace the origin of the European hunter gatherers and Neolithic European farmers to Africa, not the Levant. It also shows continuity between hunter-gather and Neolithic European populations via mtDNA haplogroup N.

Pickrell et al. (2013), has shown that Khoisan are mixed with Eurasian genes. Although Pickrell et al. (2013) believes this admixture is recent, the archaeological record indicates that the Khoisan were the first AMH to settle Western Eurasia and that it was the Khoisan who introduced genetic material into Eurasia.

Researchers have found that the ancient Europeans fail to have a genetic link with contemporary European populations (Caramelli et al., 2003). An analysis of Cro-Magnon DNA indicates that they belonged to haplogroup N. The Percentage of Cro-Magnon carrying haplogroup N, ranged from $8 \%$ to $42 \%$. Caramelli et al. (2008) also report finding haplogroup $\mathrm{H}$.

Haak et al. (2005) found that the first Neolithic farmers did not have a strong genetic influence on modern European female lineages. Like Caramelli et al. (2003), these researchers found that the farmers were predominately haplogroup (hg) N1a. The existence of the $\mathrm{N}$ haplogroup in western Europe from 24 kya (Caramilli et al., 2003), to 7500 kya (Haak et al., 2005), show continuity between the Pleistocene hunter-gatherers and Neolithic western Eurasians farmers who carried hg N.

In Africa haplogroup $\mathrm{N}$ is spread across the African continent (Winters, 2010). Common transitions for haplogroup $\mathrm{N}$ are transitions $73,7028,11,719,12,705,14,766$ and 16,223. The defining mutations of haplogroup $\mathrm{N}$ include 8701, 9540, 10,398, 10,873 and 15,301. Haplogroup $\mathrm{N}$ is a branch of L3(M, N).

Haplogroup $\mathrm{N}$ represents the ancestral mtDNA haplogroup of many Eurasian and African haplogroups including R, N1, A, I and X. The N and R haplogroups possess the mutations 10,398G > A and 10,873C > T on the line to CRS and the HVR1 mutation 16223T > C. In relation to haplogroup L3(M, N) is 94.3 kya (Gonder et al., 2006). 
In Europe only 0.2 of the population belong to haplogroup $\mathrm{N}$. The carriers of haplogroup $\mathrm{N}$ are mainly situated in Central Europe.

In Africa the $\mathrm{N}$ haplogroup is found throughout the African continent. Sub-Saharan African populations carrying haplogroup $\mathrm{N}$ belong to almost all the language families spoken in Africa including Cushitic, Nilo-Saharan, Khoisan, Niger-Congo, and Semitic.

The majority of carriers of haplogroup $\mathrm{N}$ in Africa live in Sub-Saharan Africa. In East Africa we find 85.5 percent of the populations carrying haplogroup $\mathrm{N}$. Another 14.5 percent of the carriers of haplogroup $\mathrm{N}$ live in West Africa.

The contemporary genomic data for haplogroup $\mathrm{N}$ in Africa and archaeological data indicates that this haplogroup probably appeared first in East Africa near the Great Lakes region. The geographical center for haplogroup $\mathrm{N}$ was probably Tanzania. Here we find in relative close proximity speakers of Khoisan, Niger-Congo, Cushitic and Nilo-Saharan language families that carry haplogroup N (Winters, 2010).

The Khoisan carry haplogroups L3(M, N). Before they reached Iberia, they probably stopped in West Africa.

The basal L3(M) motiff in West Africa is characterized by the Ddel site np 10394 and Alul site np 10397 associated with AF-24. This supports the view that Khoisan speakers early settled West Africa on their way to Iberia.

Granted L3 and L2 are not as old as LOd, but Gonder et al. (2006) provides very early dates for this mtDNA e.g., L3(M, N) 94.3; the SAK carry haplogroups L1c, L1, L2, L3 M, N and dates to 142.3 kya; the Hadza are L2a, L2, L3, M, N, and dates to 96.7 kya.

The dates for L1, L2, L3, M, N are old enough for the Khoisan to have taken $\mathrm{N}$ to West Africa and thence Iberia.This genetic evidence now supports Boule and Vallois (1957) of a khoisan migration into Europe.

The y-chromosome denotes the male haplogroups. Y-chromosome haplogroup A is represented among African populations. Haplogroup A has its highest frequencies among the Khoisan and Pgymies. In Table 1, we present the percentage of South African Khoisan who carry haplogroups A and B. Haplogroup A is around 140,000 years old.

In West Africa, under $5 \%$ of the NC speakers belong to group A. Most Niger-Congo speakers who belong to group A are found in East Africa and belong to A3b2-M13: Kenya (13.8) and Tanzanian (7.0\%).

The second oldest y-chromosome is haplogroup B. Haplogroup B is common among the forest people: the Pygmy groups namely the Baka and Mbuti.

Haplogroup A is largely restricted to parts of Africa, though a handful of cases have been reported in Europe and Western Asia. The clade achieves its highest modern frequencies in the Bushmen hunter-gatherer populations of Southern Africa, followed closely by many Nilotic groups in Eastern Africa. However, haplogroup A's oldest sub-clades are exclusively found in Central-Northwest Africa, where it, and consequently Y-chromosomal Adam, is believed to have originated about 140,000 years ago. The clade has also been observed at notable frequencies in certain populations in Ethiopia, as well as some Pygmy groups in Central Africa.

In a composite sample of 3551 African men, Haplogroup A had a frequency of 5.4\%. The highest frequencies of haplogroup A have been reported among the Khoisan of Southern Africa, Beta Israel, and Nilo-Saharans from Sudan.

Haplogroup A has been observed as A1 in European men in England. As A3b2, it has been observed with low frequency in Asia Minor, the Middle East, and some Mediterranean islands, among Aegean Turks, Sardinians, Palestinians, Jordanians, Yemenites, and Omanis. Without testing for any subclade, haplogroup A has been observed in a sample of Greeks from Mitilini on the Aegean island of Lesvosand in samples of Portuguese from southern Portugal, central Portugal, and Madeira.

Haplogroup B (YDNA) is localized to sub-Saharan Africa, especially to tropical forests of West-Central

Table 1. Khoisan y-chromosome haplogroups*.

\begin{tabular}{cccc}
\hline Norm & A2 haplogroup & A3b1 haplogroup & B26 haplogroup \\
64 kung & $8 \%$ & $18 \%$ & $8 \%$ \\
26 khwe & & $12 \%$ & $57 \%$ \\
7 san & $43 \%$ & & $5 \%$ \\
\hline
\end{tabular}

*After Scozzari et al., 2014. 
Africa. After Y-haplogroup A, it is the second oldest and one of the most diverse human Y-haplogroups. It was the ancestral haplogroup of not only modern Pygmies like the Baka and Mbuti, but also Hadzabe from Tanzania, who often have been considered, in large part because of some typological features of their language, to be a remnant of Khoisan people in East Africa.

Controversy surrounds the migration of AMH into western Eurasia. Olalde et al. (2014) believes that the La Bana samples indicates "the existence of a common ancient genome signature across western and central Eurasia from the Upper Paleolithic to the Mesolithic.

The La Bana population belonged to y-chromosome C6. The y-haplogroup C6 finding in Mesolithic Iberia supports the early introduction of AMH across the Straits of Gibraltar-not eastern Eurasia.

The ancestral alleles from La Bana and Luxemburg dark skinned Europeans (Olalde et al., 2014), make it clear early Europeans were not pale skinned as Klyosov (2014) alleges. This genetic evidence for dark pigmented ancient Europeans was supported by the negro skeletons associated with ancient European sites (Boule \& Vallois, 1957).

\section{Discussion}

Archaeological evidence from Africa details the expansion of AMH across Africa. There was probably a serial expansion of haplogroup N across Africa into Eurasia (Winters, 2010). Haplogroup N probably originated in the Great Lakes region of East Africa 93.4 kya (Winters, 2010). From Tanzania, Khoisan speaking people probably spread the haplogroup into Ethiopia by 80 kya. West Africa at this time and the Sahara was much wetter. This suggest that there may have been considerable threat of diseases such as sleeping sickness and sickle cell anemia; and as a result these areas were sparsely populated and haplogroup $\mathrm{N}$ did not spread into these areas until 70 kya (Winters, 2010).

Due to population increases in Ethiopia and other parts of east Africa 60 kya Sub-Saharan Africans carrying haplogroup N migrated into Yemen and on into East Eurasia (Winters, 2010).

The craniofacial evidence makes it clear that the Levantines and Ancient Europeans came from Africa (Brace et al., 2006; Holliday, 2000; Winters, 2011). They introduced SSA flora and fauna into Eurasia (Holliday, 2000). As a result we find those craniofacial features of the Grimaldi-Cro-Magnon population (Brace et al., 2006; Barral \& Charles, 1963), were shared with the Natufian population when plotted, and fall within the range of Sub-Saharan populations like the Niger-Congo speakers (Balter, 2005).

Numerous Sub-Saharan skeletons have been found in Europe dating to the Aurignacian and Neolithic periods (Brace et al., 2006; Boule \& Vallois, 1957; Diop, 1974, 1991; DuBois, 1941). Boule and Vallois (1957) observed that Sub-Saharan skeletons have been found in the Ligurian and Lombard tombs, Grotte des Enfants, Chamblandes in Switzerland, caverns of Moniat, near Dinant in Belgium. Boule and Vallois (1957) claim that these European farmers correspond to the Khoisan population. This is interesting because Brace et al. (2006) found that the craniofacial features of these early European farmers and the Natufians plotted with Sub-Saharan groups (Brace et al., 2006) just like the Aurignacians (Boule \& Vallois, 1957; Winters, 2011).

Skoglund et al. (2014) investigated the pigmentation of ancient Europeans including skeletal remains from Ajvide 5, La Brana 1, and the Iceman. The analysis by Skoglund et al. (2014) determined that the pigmentation phenotype for these Europeans was dark skin.

There are N hgs found in Africa. Haplogroups N, $\mathrm{N}^{*}$ and N1 is found in low frequencies within Sub-Saharan groups including Senegambians (Gonzalez et al., 2006), Tanzanians (Gonder et al., 2006) and modern Ethiopians (Quibtanana-Murci, 1999). In Egypt 8.8 percent of the Gurma carry hg N1b (Stevanovitch et al., 2003).

\section{Conclusion}

In conclusion, the ancient Europeans were dark skinned (Lazaridis et al., 2013; Olalde et al., 2014). They carried mtDNA haplogroups H, N, and U, and probably y-chromosomes A and C6. Some of these Blacks had blue eyes (Lazaridis et al., 2013).

Neanderthals lived in Africa at Jebel Ighoud and Haua Fteah (Ki-Zerbo, 1981). The Khoisan carried Neanderthal genes (Scozzari et al., 2014).

These Black Europeans carried haplogroups H and N. These haplogroups continue to be carried by Sub Saharan Africans (Winters, 2010). This is based on the reality that the haplogroup N1(a) is common to Senegambians, modern Ethiopians and the Dravidian speaking people of India; and the craniometric evidence indicated that the 
Aurignacian and Neolithic populations were Sub-Saharan Africans (Boule \& Vallois, 1957; Diop, 1991).

Thus, the ancient hunter-gather Europeans and European farmers were related to African groups. These dark skinned people probably planted the seeds of agriculture in ancient Europe. Interestingly, between 23,000-7000 BC the dominant haplogroup of Western Eurasians remained hg N1 (Winters, 2011).

\section{References}

Balter, M. (2005). Ancient DNA Yields Clues to the Puzzle of European Origins. Science, 310, 964-965. http://dx.doi.org/10.1126/science.310.5750.964

Barral, L., \& Charles, R. P. (1963). Nouvelles donnees anthropometriques et precision sue les affinities systematiques des negroides de Grimaldi. Bulletin du Musee d'Anthropologie Prehistorique de Monaco, 10, 123-139.

Boule, M., \& Vallois, H. V. (1957). Fossil Man. New York: Dryden Press.

Brace, C. L., Seguchi, N., Quintyn, C. B., Fox, S. C., Nelson, A. R., Manolis, S. K., \& Pan, Q. F. (2006). The Questionable Contribution of the Neolithic and the Bronze Age to European Craniofacial Form. Proceedings of the National Academy of Sciences of the United States of America, 103, 242-247. http://dx.doi.org/10.1073/pnas.0509801102

Brown, S. J. (2006). Neanderthals and Modern Humans in Western Asia. http://karmak.org/archive/2003/01/westasia.html

Canfield, V. A., Berg, A., Peckins, S. et al. (2014). Molecular Phylogeography of a Human Autosomal Skin Color Locus under Natural Selection. G3, 3, 2059-2067. http://dx.doi.org/10.1534/g3.113.007484

Caramelli, D., Lalueza-Fox, C., Vernesi, C., Lari, M., Casoli, A., Mallegni, B. C., Dupanloup, I., Bertranpetit, J., Barbujani, G., \& Bertorelle, G. (2003). Evidence for a Genetic Discontinuity between Neandertals and 24,000 Year-Old Anatomically Modern Europeans. Proceedings of the National Academy of Sciences of the United States of America, 100, 6593-6597. http://dx.doi.org/10.1073/pnas.1130343100

Caramelli, D., Milani, L., Vai, S., Modi, A., Pecchioli, E. et al. (2008). A 28,000 Years Old Cro-Magnon mtDNA Sequence Differs from All Potentially Contaminating Modern Sequences. PLoS ONE, 3, e2700. http://dx.doi.org/10.1371/journal.pone.0002700

Clark, J. D. (1977). The Origins of Domestication in Ethiopia. 5th Panafrican Congress of Prehistory and Quaternary Studies, Nairobi.

de Domínguez, E. F. (2005). Polimorfismos de DNA mitocondrial en poblaciones antiguas de la cuenca mediterránea. PhD Thesis, Barcelona: Universitat de Barcelona, Departament Biologia Animal.

Diop, A. (1974). The African Origin of Civilization. Brooklyn, NY: Lawrence Hill Books.

Diop, A. (1991). Civilization or Barbarism. Brooklyn, NY: Lawrence Hill Books.

DuBois, W. E. B. (1941). The World and Africa.

Ehret, C. (1979). On the Antiquity of Agriculture in Ethiopia. Journal of African History, 20, 161-177. http://dx.doi.org/10.1017/S002185370001700X

Gilead, I. (2005). The Upper Paleolithic Period in the Levant. Journal of World Prehistory, 5, 105-154.

Gonder, M. K., Mortensen, H. M., Reed, F. A., de Sousa, A., \& Tishkoff, S. A. (2006). Whole mtDNA Genome Sequence Analysis of Ancient African Lineages. Molecular Biology and Evolution, 24, 757-768. http://dx.doi.org/10.1093/molbev/msl209

González, A. M., Cabrera, V. M., Larruga, J. M., Tounkara, A., Noumsi, G., Thomas, B. N., \& Moulds, J. M. (2006). Mitochondrial DNA Variation in Mauritania and Mali and Their Genetic Relationship to Other Western Africa Populations. Annals of Human Genetics, 70, 631-657.

http://www.blackwell-synergy.com/doi/abs/10.1111/j.1469-1809.2006.00259.x?cookieSet=1\&journalCode=ahg http://dx.doi.org/10.1111/j.1469-1809.2006.00259.x

Haak, W., Forster, P., Bramanti, B., Matsumura, S., Brandt, G., Tänzer, M., Villems, R., Renfrew, C., Gronenborn, D., Alt, K. W., \& Burger, J. (2005). Ancient DNA from the First European Farmers 7500-Year-Old Neolithic Sites. Science, 310, 1016-1018.

Holliday, T. (2000). Evolution at the Crossroads: Modern Human Emergence in Western Asia. American Anthropologist, 102, 54-68.

Ki-Zerbo, J. (1981). Unesco General History of Africa Vol. 1: Methodology and African Prehistory. 572.

Klyosov, A. A. (2014). Reconsideration of the "Out of Africa” Concept as Not Having Enough Proof. Advances in Anthropology, 4, 18-37. http://www.scirp.org/journal/aa http://dx.doi.org/10.4236/aa.2014.41004

Lazaridis, J., Patterson, N., Mittnik, A. et al. (2013). Ancient Human Genomes Suggest Three Ancestral Populations for Present-Day Europeans. http://biorxiv.org/content/biorxiv/early/2013/12/23/001552.full.pdf 
Olalde, I., Allentoft, M. E., Sanchez-Quinto, F., Santpere, G., Chiang, C. W. K., DeGiorgio, M. et al. (2014). Derived Immune and Ancestral Pigmentation Alleles in a 7,000-Year-Old Mesolithic European. Nature, 507, 225-228. http://dx.doi.org/10.1038/nature12960

Pickrell, J. K., Patterson, N., Loh, P. R., Lipson, M., Berger, B., Stoneking, M., Pakendorf, B., \& Reich, D. (2013). Ancient West Eurasian Ancestry in Southern and Eastern Africa. http://arxiv.org/abs/1307.8014

Prufer, K., Racimo, F., Patterson, N., Jay, F., Sankararaman, S., Sawyer, S. et al. (2014). The Complete Genome Sequences of Neanderthal from the Altai, Mountains. Nature, 505, 43-49.

Quibtanana-Murci, L., Semino, O., Bandelt, H. J., Passaro, G., McElreadey, K., \& Santachiara-Benerecetti, A. S. (1999). Genetic Evidence of an Early Exit of Homo Sapiens from Africa through Eastern Africa. Nature Genetics, 23, 437-441. http://dx.doi.org/10.1038/70550

Rito, T., Richard, M. B., Fernandes, V., Alshamal, F., Cerny, V., Pereira, L., \& Soares, P. (2013). The First Modern Human Dispersals aross Africa. PLoS ONE, 8, e80031.

Scozzari, R., Massaia, A., Trombatta, B., Bellusci, G., Myres, N. M., Novelletto, A., \& Cruciani, F. (2014). An Unbiased Resource of Novel SNP Markers Provides a New Chronology for Human Y-Chromosome and Reveals a Deep Phylogenetic Structure in Africa. Genome Research.

Skoglund, P., Malmström, H., Omrak, A., Raghavan, M., Valdiosera, C., Günther, T., Hall, P., Tambets, K., Parik, J., Sjögren, K. G., Apel, J., Willerslev, E., Storå, J., Götherström, A., \& Jakobsson, M. (2014). Genomic Diversity and Admixture Differs for Stone-Age Scandinavian Foragers and Farmers. Science, 344, 747-750.

http://dx.doi.org/10.1126/science.1253448

Stevanovitch, A., Gilles, A., Bouzaid, E., Kefi, R., Paris, F., Gayraud, R. P., Spadoni, J. L., El-Chenawi, F., \& Béraud-Colomb, E. (2003). Mitochondrial DNA Sequence Diversity in a Sedentary Population from Egypt. Annals of Human Genetics, 68, 23-29. http://dx.doi.org/10.1046/j.1529-8817.2003.00057.x

Steven, L. K., Stiner, M. C., Reese, D. S., \& Gulec, E. (2001). Ornaments of the Earliest Upper Paleolithic: New Insights from the Levant. Proceedings of the National Academy of Sciences of the United States of America, 98, 7641-7646. http://dx.doi.org/10.1073/pnas.121590798

Wendorf, F. (1968). The History of Nubia. Dallas, TX.

Winters, C. (2008). Aurignacian Culture: Evidence of Western Exit for Anatomically Modern Humans. South Asian Anthropologist, 8, 79-81.

Winters, C. (2010). Origin and Spread of the Haplogroup N. Bioresearch Bulletin, 3, 116-122.

Winters, C. (2011). The Gibraltar out of Africa Exit for Anatomically Modern Humans. WebmedCentral BIOLOGY, 2, Article ID: WMC002311. http://www.webmedcentral.com/article_view/2311 
Scientific Research Publishing (SCIRP) is one of the largest Open Access journal publishers. It is currently publishing more than 200 open access, online, peer-reviewed journals covering a wide range of academic disciplines. SCIRP serves the worldwide academic communities and contributes to the progress and application of science with its publication.

Other selected journals from SCIRP are listed as below. Submit your manuscript to us via either submit@scirp.org or Online Submission Portal.
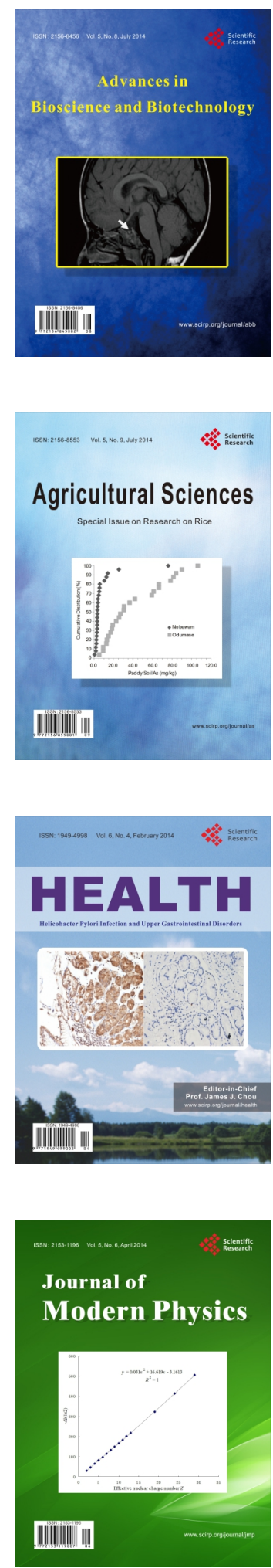
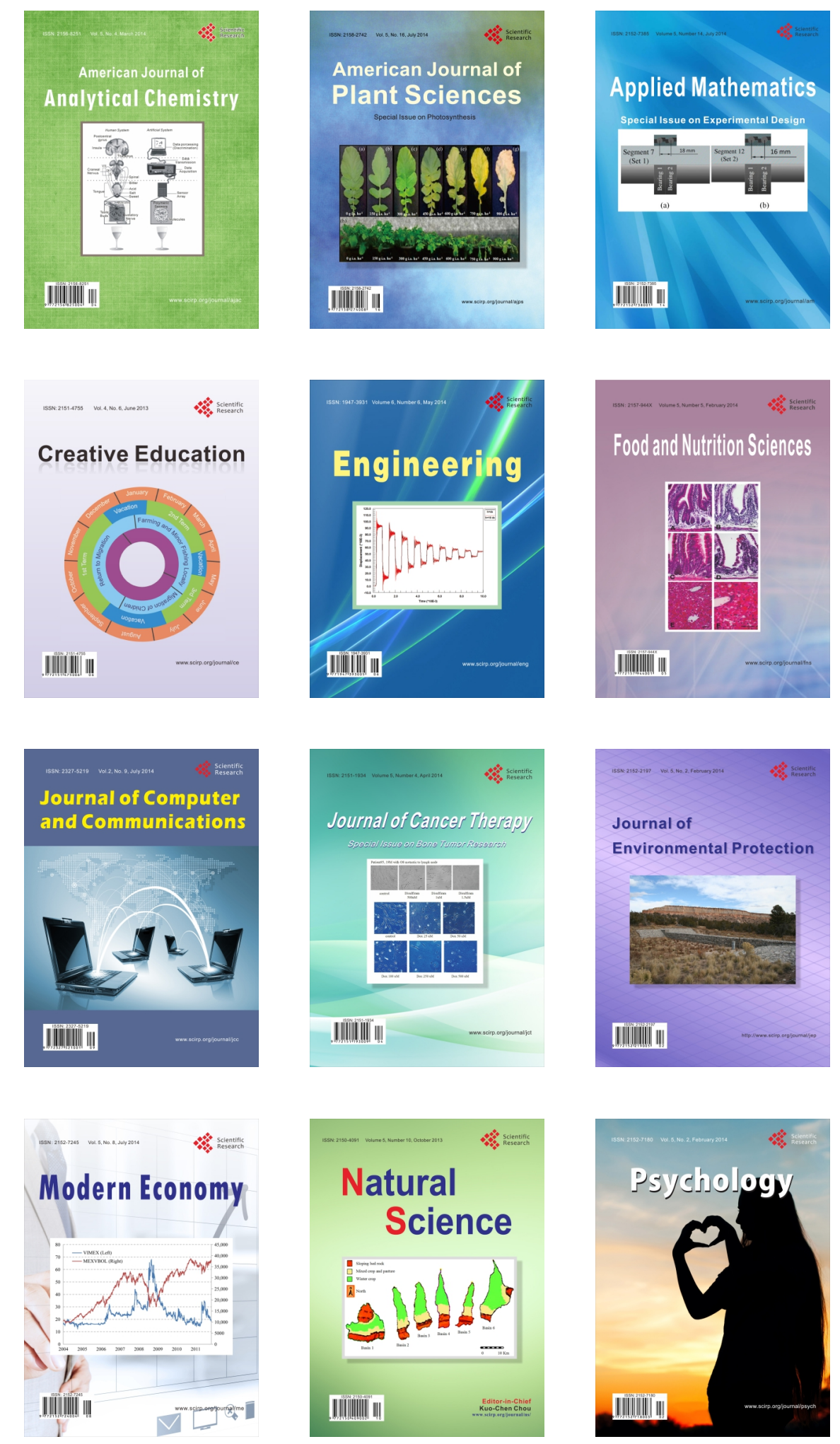